\title{
Endocuff-Assisted Colonoscopy-A Novel Accessory in Improving Adenoma Detection Rate: A Review of the Literature
}

\author{
Rashmee Patil ${ }^{1}$, Mel A. Ona² ${ }^{2}$ Emmanuel Ofori ${ }^{2}$ and Madhavi Reddy ${ }^{2}$ \\ ${ }^{1}$ Department of Internal Medicine, Mount Sinai West, New York, NY, ${ }^{2}$ Department of Gastroenterology and Hepatology, The Brooklyn Hospital \\ Center, The Icahn School of Medicine at Mount Sinai, Brooklyn, NY, USA
}

Endocuff (Arc Medical Design) is a U.S. Food and Drug Administration-approved device that is attached like a cap to the distal tip of the colonoscope; it is used to improve adenoma detection rates during colonoscopy. The aim of this review was to summarize and evaluate the clinical and technical efficacy of Endocuff in improving adenoma detection rate. A comprehensive literature review was performed to identify studies describing this technique. In this review article, we have summarized case series and reports describing Endocuff use and results. The reported indications, results, limitations, and complications are discussed. Clin Endosc 2016;49:533-538

Key Words: Adenoma detection rate; Adenoma; Colorectal neoplasms; Endocuff; Colonoscopy

\section{INTRODUCTION}

The adenoma detection rate $(\mathrm{ADR})$ is an important quality measure of screening colonoscopy delivery and is crucial for reducing colorectal cancer (CRC)-related morbidity and mortality. ADR is defined as the percentage of patients aged 50 years or older who are undergoing first-time colonoscopy for CRC screening, who have at least one adenoma detected and removed. ${ }^{1,2}$ The ADR differs widely among populations, reaching approximately $22 \%$ in a large screening population. ${ }^{3}$ Up to $25 \%$ of adenomas are reportedly missed during colonoscopy because of poor colon preparation and poor visualization behind mucosal folds. Flat lesions in the right side of the colon can be particularly difficult to detect. ADR is an important quality measure because it is inversely associated with the risk of interval CRC. Recent studies estimate that each $1 \%$

Received: January 27, 2016 Revised: March 29, 2016

Accepted: April 11, 2016

Correspondence: Rashmee Patil

Department of Internal Medicine, Mount Sinai West, 1000 10th Ave, New York, NY 10019, USA

Tel: +1-409-656-6475, Fax: +1-409-656-6475, E-mail: rashmee84@gmail.com

(c) This is an Open Access article distributed under the terms of the Creative Commons Attribution Non-Commercial License (http://creativecommons.org/ licenses/by-nc/3.0) which permits unrestricted non-commercial use, distribution, and reproduction in any medium, provided the original work is properly cited. increase in the ADR lowers the risk of interval cancers by $3 \%{ }^{4-6}$

Several endoscopic innovations and devices have been developed to increase the ADR, with either limited benefit (e.g., visual enhancement technologies, cap) or high technical impact (Third Eye Retroscope; Avantis Medical Systems, Sunnyvale, CA, USA; $330^{\circ}$ full-spectrum endoscopy).

Since 2012, a new endoscopic device called Endocuff (EC; Arc Medical Design, Leeds, United Kingdom) has been available (Figs. 1, 2). EC is a U.S. Food and Drug Administration-approved device that is attached like a cap to the distal tip of the colonoscope. The device has eight flexible branches arranged in two rows. These branches are used to flatten the folds of the colon while withdrawing the colonoscope, allowing for improved visibility behind the folds. ${ }^{7}$

There are limited recent publications summarizing the clinical and technical success of EC in improving ADR during colonoscopy. In the present review, we review the published literature and describe the indications, results, limitations, and complications reported with EC.

\section{MATERIALS AND METHODS}

Extensive English language literature search was conducted using PubMed, Medline, and Google to identify peer-re- 


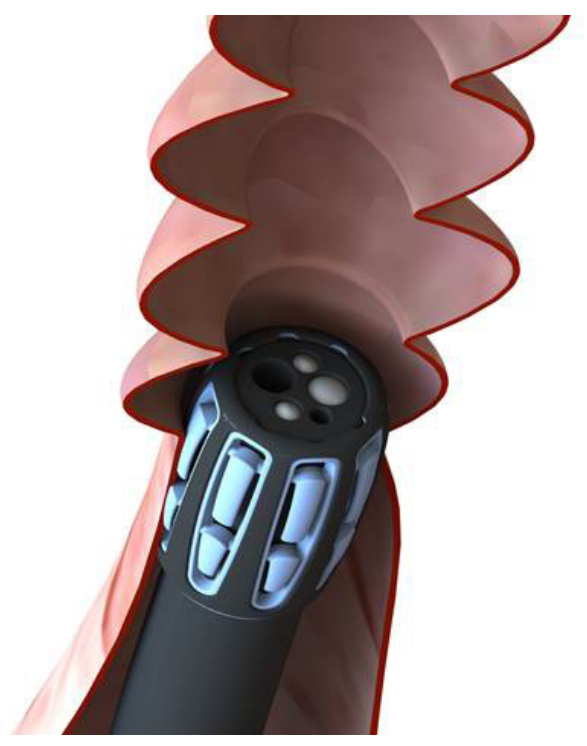

Fig. 1. Endocuff, attached like a cap to the distal tip of the colonoscope.

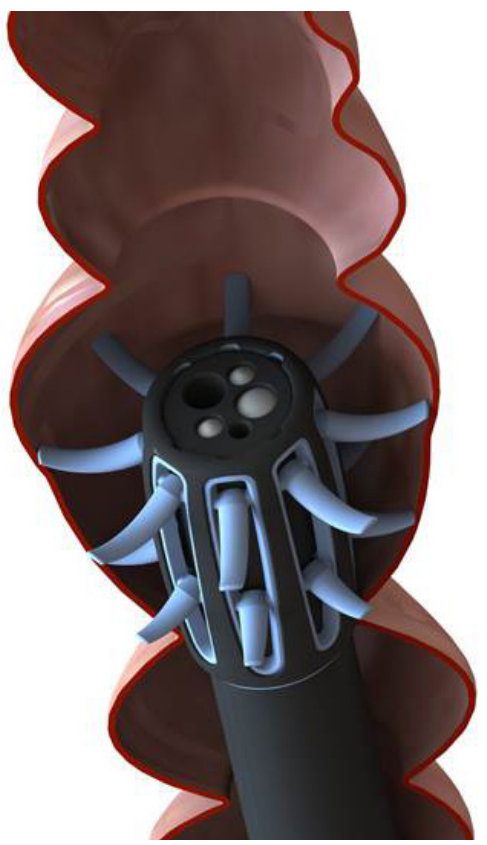

Fig. 2. Endocuff with eight flexible branches arranged in two rows.

viewed original and review articles by using the keywords 'Endocuff,' 'adenoma detection rate,' 'colonoscopy', and 'colorectal cancer.' Only human studies were included. The references of pertinent studies were manually searched to identify additional relevant studies. The indications, procedural details, technical and clinical success rates, complications, and limitations were considered as part of the inclusion criteria. Search results yielded mostly small sample sized prospective studies and case reports, which limited statistical analysis in the form of meta-analysis. None of the authors has any conflicts of interest or financial relationships with the company that produces or distributes the device described in this review article.

\section{RESULTS}

Seven original published articles were considered appropriate for inclusion. All seven articles were case series. Tables 1, 2 summarize the included studies.

\section{Demographics}

As shown in Table 1, most of the published cases were reported from European countries. A total of 2,761 patients were included across all studies. Five of the seven studies reported the gender of the patients included in the study. Those five studies reported that $49.2 \%(1,086 / 2,207)$ were female and $50.8 \%(1,121 / 2,207)$ were male. Mean age calculated from all reported cases was 62.4 years (Table 1 ).

\section{Indications}

Indications for undergoing colonoscopy included screening for CRC, surveillance of previously detected polyps, or diagnosis of symptoms such as abdominal pain or anemia. ${ }^{1-4,6-8}$ Van Doorn et al. ${ }^{6}$ also included patients with positive fecal immunochemical testing results in their screening cohort.

\section{Technical and clinical findings/success rates}

Five of the seven studies included were comparative studies. $^{2,4,6-8}$ Patients were randomized into either a standard colonoscopy group or an Endocuff-assisted colonoscopy (EAC) group. In four of these five studies, the EAC group had a significantly higher ADR (Table 2). In the study by Van Doorn et al., ${ }^{6}$ the ADR between the standard and EAC groups was similar and EC did not seem to increase the accuracy of colonoscopy. For those studies that included procedural data, cecal intubation was reported in $97 \%$ of patients undergoing EAC. Withdrawal time and cecal intubation time did not significantly differ between the EAC and standard colonoscopy groups; however, the studies reporting this data were very few for a conclusion to be made. Polyp detection rate (PDR) was significantly higher in EAC groups as compared to standard groups across all comparative studies, regardless of indication for colonoscopy. ADR was also superior with EC in detection of right-sided adenomas in those studies that reported location of adenomas. Furthermore, for studies that reported polyp histology, advanced adenomas were more frequently detected in the EAC group than in the standard group. In the study by Sawatzki et al., ${ }^{1}$ advanced adenomas were detected and removed in $13.5 \%$ patients. These included 11 adenomas greater than $10 \mathrm{~mm}$, two tubulovillous adenomas, and one 
Table 1. Characteristics of Patients in Reported Endocuff Studies

\begin{tabular}{|c|c|c|c|c|c|}
\hline Study & Country & No. of patients & Age, yr & Sex, male/female & Type of study \\
\hline Sawatzki et al. $(2015)^{1}$ & Switzerland & 104 & $59^{\text {a) }}$ & $57 / 47$ & Case series \\
\hline Floer et al. $(2014)^{2}$ & Germany & 492 & $64^{\text {a) }}$ & $235 / 257$ & Case series \\
\hline Lenze et al. $(2014)^{3}$ & Germany & 50 & $57^{\text {a) }}$ & $31 / 19$ & Case series \\
\hline Chin et al. $(2015)^{4}$ & California, USA & 236 & NM & NM & Case series \\
\hline Van Doorn et al. $(2015)^{6}$ & The Netherlands & $\begin{array}{c}\text { EC, } 530 \\
\text { Standard, } 533\end{array}$ & $65^{\text {a) }}$ & $\begin{array}{c}\text { EC, } 264 / 266 \\
\text { Standard, } 285 / 248\end{array}$ & Case series \\
\hline Marsano et al. $(2014)^{7}$ & Not reported & $\begin{array}{c}\text { EC, } 165 \\
\text { Standard, } 153\end{array}$ & NM & NM & Case series \\
\hline Biecker et al. $(2015)^{8}$ & Germany & 498 & $67^{\text {a) }}$ & $249 / 249$ & Case series \\
\hline
\end{tabular}

NM, not mentioned; EC, Endocuff; Standard, standard colonoscopy technique.

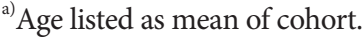

neuroendocrine carcinoid. In the study by Floer et al., ${ }^{2}$ a statistically significant difference was shown in the advanced ADR for non-invasive low-grade dysplasia in the EAC group versus the standard group. The technical success rate was $100 \%$ across all studies using the EC assisted approach, and no major complications were noted. Most studies did not measure clinical success rates, as the patients undergoing the procedure were predominantly asymptomatic at the time of screening colonoscopy.

\section{Complications and adverse outcomes}

Four studies reported minor complications, as summarized in Table $2 .^{1-3,8}$ The study by Biecker et al. ${ }^{8}$ was the only study that reported loss of the cuff as an adverse outcome of the procedure. The majority of included studies noted minor mucosal bleeding and post-procedural bleeding as the most common complication.

\section{Limitations}

Thus far, clinically successful cases have been published with few complications reported, but this may be due to a publication bias, as the procedure is fairly new. As more technically and clinically relevant cases are published, additional data may become available for assessment regarding the impact of EAC on colon cancer-related morbidity and mortality.

\section{DISCUSSION}

Colonoscopy performed as a part of colon cancer prevention programs remains the gold standard for CRC screening. The ADR seems to be most crucial in preventing interval colon cancer, as a suboptimal ADR is significantly associated with a higher incidence of CRC. An ADR of at least $20 \%$ is generally accepted as sufficient for colon cancer prevention programs and should be the standard for colon cancer prevention centers. ${ }^{9-11}$ Recently, many studies have aimed to achieve a better ADR through various accessory devices (cap assistance, third eye retroscope, EC) and advancements in endoscope design (full spectrum endoscopy system, balloon-assisted colonoscopy, confocal laser endomicroscopy). As a simple attachment to the distal tip of the colonoscope, the EC is an effective and inexpensive alternative for increasing the ADR without restricting the field of vision. The benefit of $\mathrm{EC}$ is that it is a safe measure that improves PDR and ADR in a screening population with no severe adverse events, even in patients with diverticulosis. Furthermore, the cecal intubation time is not lengthened, and a significant number of small polyps can be detected in the right side of the colon. ${ }^{12,13}$

Other technical innovations, like cap-assisted colonoscopy (CAC), back-to-back colonoscopy, or narrow band imaging, have also been evaluated for higher polyp and ADRs. CAC shows conflicting results in terms of improving ADR. In a study by Rastogi et al., ${ }^{10}$ ADR improved with CAC; in contrast, a recently published two-center randomized controlled trial conducted by de Wijkerslooth et al. ${ }^{14}$ failed to show an improvement in ADR. When compared to EC, more training is likely to be necessary due to the technical nature of CAC and its effect on the view of the examiner. ${ }^{8}$ Furthermore, during $\mathrm{CAC}$, fecal material can become trapped in the cap and impair the visual field; repeated cleaning maneuvers can be time consuming. ${ }^{14}$ In our review of pertinent articles, there was no mention regarding the learning curve timing for precise use of EAC. Most endoscopists included in these case series were experienced and had performed a large volume of colonoscopies prior to use of EAC.

Another upcoming device aimed to increase ADR is the NaviAid G-EYE System (SMART Medical Systems Ltd., Raanana, Israel), which includes the G-EYE balloon colonoscope and the NaviAid inflation system. The NaviAid G-EYE 
$C_{\text {cunnch enooscopy }}$

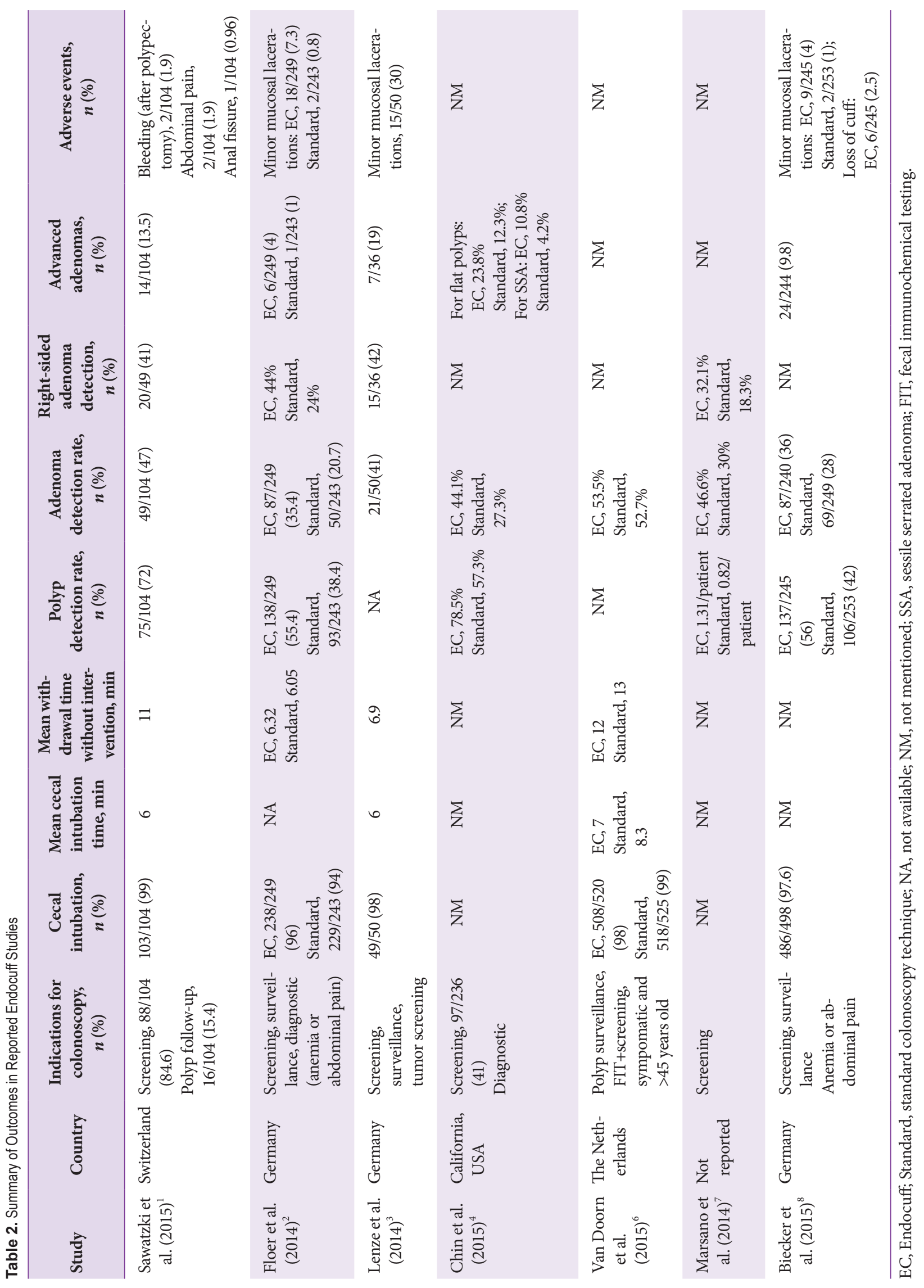


colonoscope permanently integrates a balloon onto the flexible tip of a standard colonoscope and is inflatable, reusable, and re-processable. The integrated balloon can be inflated by the endoscopist upon colonoscope withdrawal, to carry out balloon-assisted colonoscopy. The mechanical flattening and straightening of the colonic mucosal folds with the inflated balloon allows visualization of hidden anatomical areas; thus, increasing the $\mathrm{ADR} .{ }^{15}$ In a prospective study by Hasan et al., ${ }^{16}$ the diagnostic yield of balloon-assisted colonoscopy versus that of standard forward-viewing colonoscopy in the detection of simulated polyps in a colon model was compared. Median PDR for all simulated polyps was significantly higher with the G-EYE balloon colonoscope as compared to that with standard forward-viewing colonoscopy. In the first human study using G-EYE, Gralnek ${ }^{15}$ carried out a single-center, prospective cohort study that looked at patients referred for CRC screening, polyp surveillance, or diagnostic evaluation. A total of 44 polyps in 25 of 47 subjects were identified by the G-EYE balloon colonoscope, resulting in a 53.2\% PDR. The investigators reported that $36 / 44$ (81.8\%) polyps were 'adenomas', with 21/47 subjects having at least one adenoma, yielding a $44.7 \%$ ADR. Gralnek ${ }^{15}$ concluded that G-EYE appeared to be safe and feasible to use, as the primary end point of this study was safety and efficacy of the device. In a multicenter, randomized, controlled trial comparing standard colonoscopy with G-EYE balloon colonoscopy, Shpak et al. ${ }^{17}$ reported that when compared with standard colonoscopy, G-EYE balloon colonoscopy detected an additional 17 adenomas, representing $81 \%$ more than that in the group undergoing standard colonoscopy. Furthermore, there was only a $7.5 \%$ adenoma miss rate reported with balloon colonoscopy. ${ }^{16-18}$

As shown in our review article, EAC might have some advantages over standard colonoscopy. Our findings suggest that EAC may result in higher overall ADR and PDR and may be more effective in detecting right-sided adenomas and allowing better inspection of proximal colonic folds. Detection of these polyps that are more likely to be visualized hidden, especially on the reverse side of the mucosal folds, promoted higher ADR and PDR in the EAC group in the studies included in our review. Findings also suggested that EC might facilitate easier polypectomy. This could be as a result of higher friction that allows for avoidance of sudden slippage of the colonoscope because the distal row of EC arms can be used to expose the polyp. Therefore, polypectomy procedures seem to be easier due to a more stable colonoscope position and better visualization by EC. Additionally, EC does not impair the direct wide-angle view of the colonoscope. Finally, in the studies included in our review, no major complications were reported for EC and its use in screening colonoscopy. ${ }^{5.7,8}$

\section{CONCLUSION}

In conclusion, the EC is a new, safe, and promising attachable device for screening colonoscopy. As a result of our literature review, the EC seems to provide benefits over standard colonoscopy in facilitating complete colonoscopy, improving the visualization of the colonic mucosa, detecting hidden polyps, and improving the overall PDR and ADR. The use of $\mathrm{EC}$ is safe and feasible. Recently, the EC device has undergone additional development, with longer arms (EC vision) with the potential to improve ADR further. ${ }^{8}$

As previously discussed, improving the ADR correlates with a decrease in colon cancer risk. Future follow-up studies are necessary to demonstrate the impact of EAC on colon cancer-related morbidity and mortality before broad use of the EC device in colon cancer prevention programs can be recommended.

Conflicts of Interest

The authors have no financial conflicts of interest.

\section{REFERENCES}

1. Sawatzki M, Meyenberger C, Marbet UA, Haarer J, Frei R. Prospective Swiss pilot study of Endocuff-assisted colonoscopy in a screening population. Endosc Int Open 2015;3:E236-E239.

2. Floer M, Biecker E, Fitzlaff R, et al. Higher adenoma detection rates with endocuff-assisted colonoscopy: a randomized controlled multi+center trial. PLoS One 2014;9:e114267.

3. Lenze F, Beyna T, Lenz P, Heinzow HS, Hengst K, Ullerich H. Endocuff-assisted colonoscopy: a new accessory to improve adenoma detection rate? Technical aspects and first clinical experiences. Endoscopy 2014;46:610-614.

4. Chin M, Chen CL, Karnes WE. Improved polyp detection among high risk patients with Endocuff. Gastrointest Endosc 2015;81(5 Suppl):AB283.

5. Pioche M, Matsumoto M, Takamaru H, et al. Endocuff-assisted colonoscopy increases polyp detection rate: a simulated randomized study involving an anatomic colorectal model and 32 international endoscopists. Surg Endosc 2016;30:288-295.

6. Van Doorn SC, Van Der Vlugt M, Depla AC, et al. Adenoma detection with Endocuff colonoscopy vs conventional colonoscopy: a multicenter randomised controlled trial. Gastrointest Endosc 2015;81(5 Sup$\mathrm{pl}): \mathrm{AB} 145$.

7. Marsano J, Tzimas D, Mckinley M, et al. Endocuff assisted colonoscopy increases adenoma detection rates: a multi-center study. Gastrointest Endosc 2014;79(5 Suppl):AB550.

8. Biecker E, Floer M, Heinecke A, et al. Novel endocuff-assisted colonoscopy significantly increases the polyp detection rate: a randomized controlled trial. J Clin Gastroenterol 2015;49:413-418.

9. Heresbach D, Barrioz T, Lapalus MG, et al. Miss rate for colorectal neoplastic polyps: a prospective multicenter study of back-to-back video colonoscopies. Endoscopy 2008;40:284-290.

10. Rastogi A, Bansal A, Rao DS, et al. Higher adenoma detection rates with cap-assisted colonoscopy: a randomised controlled trial. Gut 2012;61:402-408.

11. Uraoka T, Tanaka S, Matsumoto T, et al. A novel extra-wide-angle-view colonoscope: a simulated pilot study using anatomic colorectal models. 
Gastrointest Endosc 2013;77:480-483.

12. Gralnek IM, Carr-Locke DL, Segol O, et al. Comparison of standard forward-viewing mode versus ultrawide-viewing mode of a novel colonoscopy platform: a prospective, multicenter study in the detection of simulated polyps in an in vitro colon model (with video). Gastrointest Endosc 2013;77:472-479.

13. Hewett DG, Rex DK. Miss rate of right-sided colon examination during colonoscopy defined by retroflexion: an observational study. Gastrointest Endosc 2011;74:246-252.

14. de Wijkerslooth TR, Stoop EM, Bossuyt PM, et al. Adenoma detection with cap-assisted colonoscopy versus regular colonoscopy: a randomised controlled trial. Gut 2012;61:1426-1434.

15. Gralnek IM. Emerging technological advancements in colonoscopy: Third Eye ${ }^{\circledR}$ Retroscope $^{\circledR}$ and Third Eye ${ }^{\circledR}$ Panoramic ${ }^{\mathrm{TM}}$, Fuse ${ }^{\circledR}$ Full Spec- trum Endoscopy ${ }^{\circledR}$ colonoscopy platform, Extra-Wide-Angle-View colonoscope, and NaviAid ${ }^{\mathrm{TM}}$ G-EYE ${ }^{\mathrm{TM}}$ balloon colonoscope. Dig Endosc 2015;27:223-231.

16. Hasan N, Gross SA, Gralnek IM, Pochapin M, Kiesslich R, Halpern Z. A novel balloon colonoscope detects significantly more simulated polyps than a standard colonoscope in a colon model. Gastrointest Endosc 2014;80:1135-1140.

17. Shpak B, Halpern Z, Kiesslich R, Moshkowitz M, Santo E, Hoff man A. A novel balloon-colonoscope for increased polyp detection rate: results of a randomized tandem study. United Eur Gastroenterol J 2013;1(Suppl 1):A87.

18. Gralnek IM, Suissa A, Domanov S. Safety and effi cacy of a novel balloon colonoscope: a prospective cohort study. Endoscopy 2014;46:883887. 